\title{
Expert System Analysis of TIG Molten Weld Metal Fluidity Using the Bond Dimensionless Number
}

\author{
Okhigbochie.K ${ }^{1}$ Achebo .J.I $\mathrm{I}^{2}$ and Ozigagun A. ${ }^{3}$ \\ Department of Production Engineering, Faculty of Engineering, University of Benin, P.M.B 1154, Benin City, Edo State, \\ Department of Production Engineering, Faculty of Engineering, University of Benin, P.M.B 1154, Benin City, Edo State, \\ Department of Production Engineering, Faculty of Engineering, University of Benin, P.M.B 1154, Benin City, Edo State, Nigeria
}

\begin{abstract}
The different modes of molten metal transfer makes up a critical aspect of welding behavior which significantly affects weld quality, so having basic understanding of the fluidity behavior of the molten weld metal will help Fabrication experts to produce weld structures with optimal strength and quality. In this present work, the Expert analysis of TIG molten weld metal fluidity using the Bond dimensionless Number was achieved. An expert experimental design was done generating 30 sets of experimental runs considering current voltage wire diameter and wire feed rate and the bond dimensionless number as response. The second order quadratic model was developed employing the response surface methodology. A model having $89 \%$ coefficient of determination and p-value of $<0.0001$. The result obtained showed that current has a very significant effect on the bond number indicating that a higher current will minimize the bond which translates into an improved fluidity of the TIG molten weld metal.
\end{abstract}

Keywords:- Bond Number, Dimensionless, Expert System, Mild Steel, Tungsten Inert Gas, Fluidity.

\section{INTRODUCTION}

Fluidity is a major factor that influences the strength and quality of most welding process.having a clear cut understanding of the fluidity behavior of the molten weld metal is very important as this allows the liquid metal to flow through a particular distance till it gets to its solidus temperature and solidify. The maximum distance the alloy travels ensures the fluidity of the metal. The theoretical fluid dynamics value and the computational fluid dynamics value was compared using the ANSYS simulation software[1].The effect of temperature field ,electromagnetic force field and the the velocity field, on the weld pool of gas metal arc welding was investigated and modelled,considering the interaction of forces such as surface tension,electromagnetic and buoyant forces between the weld pool and the molten filler metal droplets. The mathematical mode developed can be employed to analyze the fluid dynamics and thermal dynamics in both the Gas Metal Arc and gas tungsten arc welding processes.. As expected, both the buoyancy and surface tension little effect in GMA weld pool geometry[2].Experimental studies of the effect of the viscous dissipation on the surface tension and its role on the shape of weld pool was done. The results obtained revealed that the presence of titanium affects the role of sulfur as surfactant element. Titanium in the presence of carbon and oxygen, titanium forms solid compounds which affect the Marangoni convection due to the sulfur element in the weld pool. It was expected that the viscosity of metal liquid can be altered by the presence of titanium leading to larger weld bead[3].In the measurements of the surface tension and the dynamic viscosity of molten materials.the following steps were taken. Levitating and melting a small sample of material in a high vacuum using a high temperature electrostatic levitator, the resonant oscillation of the drop was induced by applying a low level AC electric field pulse at the drop of resonance frequency, the transient signals which followed the pulses were recorded, and both the surface tension and the viscosity were extracted from the signal[4].Many studies have addressed the influence of surface active elements on the weld pool fluid flow which strongly affects the weld pool geometry[5].Atoms close to a free surface have partially unfilled coordination shells requiring higher energy states which result in surface tension or surface energy[6].The different modes of molten metal transfer makes up a critical aspect of welding behavior which significantly affects weld quality[7]. During Gas Metal Arc Welding (GMAW), the metal metal droplet transfer can be simply described as a superheated molten metal drop transporting from the electrode tip to the weld pool[8].The molten metal hydrodynamics in weld pools is quite complex and often the flow is heavily unstable, as characterized by large volatilities observed in the liquid surface[9].The chemistry and physics of the GMAW is highly randomized and non static. The process itself is very complex,as the molten metal detaches under constant voltage This is because it has to endure the influence of several constant and determinable, as well as, erratic and nebulous physical and chemical interactions[10].

\section{RESEARCH METHODOLOGY}

\section{A. Design of Experiment}

In this study a scientific approach of planning the experimental process known as Design of experiment is employed.a computer software design expert 7.0 was used to generate the experimental matrix ,it helps to combine the process parameters optimally, which gives the highest number of experimental runs. The expert system graphic user interphase is shown below. 


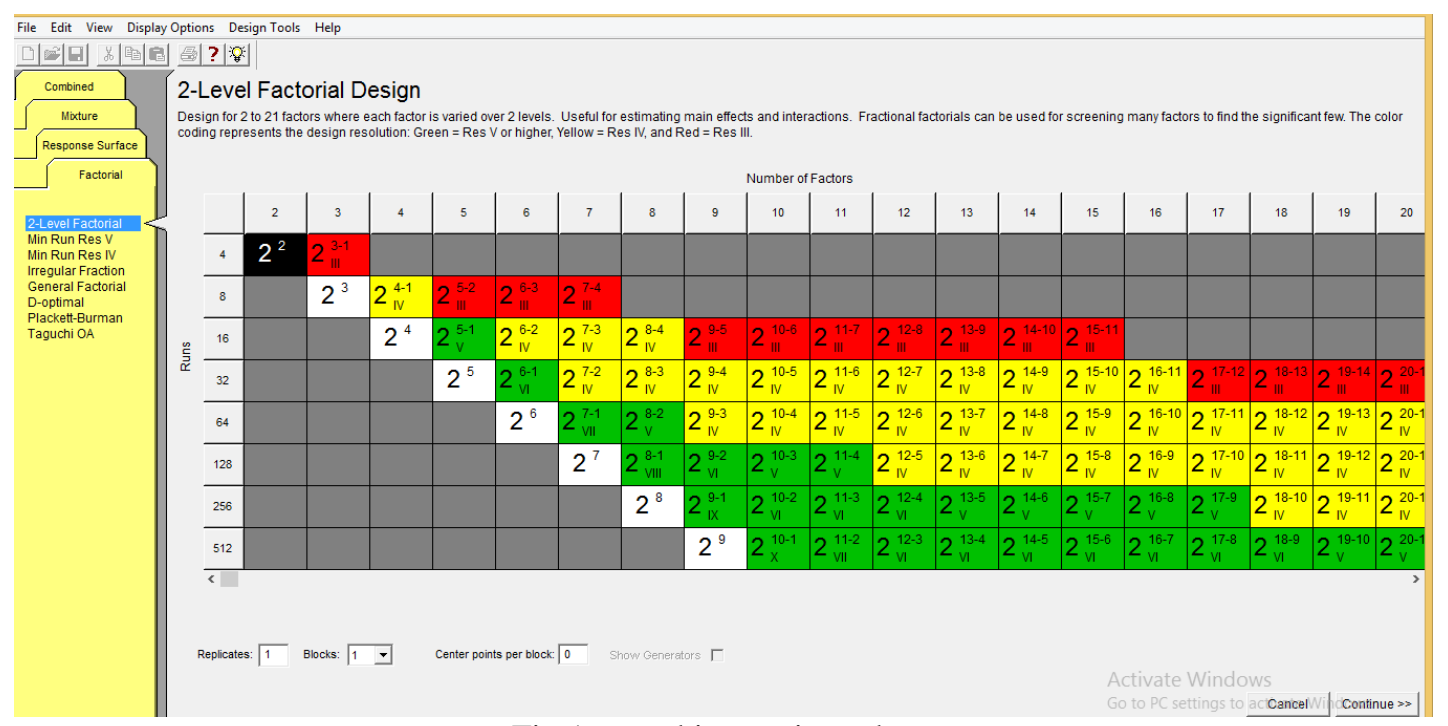

Fig 1:- graphic user interphase

The number of input parameters determines the type of experimental design. In this study four input parameters were considered, such as welding current, wire diameter, wire feed rate and voltage. The CCD central composite design was selected as the most suitable experimental design for this study. The input factors considered and their levels are shown in the table below.

\begin{tabular}{|c|c|c|c|c|}
\hline Parameters & Unit & Symbol & Coded value & Coded value \\
\hline & & & Low(-1) & High $(+1)$ \\
\hline Current & Amp & A & 110 & 40 \\
\hline Wire diameter & Mm & WD & 1.6 & 22 \\
\hline Voltage & Volt & V & 18 & 45 \\
\hline Wire feed rate & $\mathrm{mm} / \mathrm{s}$ & WFR & 25 & 4 \\
\hline
\end{tabular}

Table 1:- Process parameters and their levels

The central composite design generated thirty experimental runs with the bond number as the response ,the experimental results is shown in table 2 below.

\begin{tabular}{|c|c|c|c|c|}
\hline Current & Voltage & Wire diameter & Wire feed & Bond \\
\hline 190.00 & 18.00 & 1.60 & 25.00 & 0.4 \\
\hline 110.00 & 22.00 & 1.60 & 45.00 & 1.6 \\
\hline 110.00 & 18.00 & 4.00 & 45.00 & 1.5 \\
\hline 190.00 & 22.00 & 4.00 & 45.00 & 1.5 \\
\hline 110.00 & 18.00 & 1.60 & 45.00 & 2.4 \\
\hline 150.00 & 20.00 & 2.80 & 35.00 & 2.7 \\
\hline 150.00 & 20.00 & 2.80 & 35.00 & 1.6 \\
\hline 150.00 & 20.00 & 2.80 & 35.00 & 1.2 \\
\hline 110.00 & 18.00 & 4.00 & 25.00 & 1.4 \\
\hline 110.00 & 22.00 & 1.60 & 25.00 & 2.4 \\
\hline 150.00 & 20.00 & 2.80 & 35.00 & 3.4 \\
\hline 150.00 & 20.00 & 2.80 & 35.00 & 1.2 \\
\hline 150.00 & 20.00 & 2.80 & 35.00 & 1.1 \\
\hline 150.00 & 20.00 & 0.40 & 35.00 & 4.2 \\
\hline 110.00 & 22.00 & 4.00 & 45.00 & 0.7 \\
\hline 110.00 & 22.00 & 4.00 & 25.00 & 0.4 \\
\hline 70.00 & 20.00 & 2.80 & 35.00 & 0.5 \\
\hline 150.00 & 16.00 & 2.80 & 35.00 & 55.00 \\
\hline 150.00 & 20.00 & 2.80 & 25.00 & \\
\hline 190.00 & 18.00 & 4.00 & & \\
\hline
\end{tabular}


ISSN No:-2456-2165

\begin{tabular}{|c|c|c|c|c|}
\hline 110.00 & 18.00 & 1.60 & 25.00 & 1.4 \\
\hline 150.00 & 20.00 & 5.20 & 35.00 & 0.3 \\
\hline 150.00 & 24.00 & 2.80 & 35.00 & 0.4 \\
\hline 190.00 & 22.00 & 4.00 & 25.00 & 0.35 \\
\hline 190.00 & 18.00 & 1.60 & 45.00 & 0.4 \\
\hline 190.00 & 22.00 & 1.60 & 25.00 & 0.6 \\
\hline 190.00 & 22.00 & 1.60 & 45.00 & 0.4 \\
\hline 190.00 & 18.00 & 4.00 & 45.00 & 1.2 \\
\hline 230.00 & 20.00 & 2.80 & 35.00 & 0.4 \\
\hline 150.00 & 20.00 & 2.80 & 15.00 & \\
\hline
\end{tabular}

Table 2:- Experimental Results

\section{B. Experimental procedure}

The experimental design was used as a guide to conduct the experiment, the coupons was cut from mild steel plate of $10 \mathrm{~mm}$ thickness with a Power HacksawT, the edges of the specimen were grinded and cleaned with sand paper. The mild steel plates were tightly clamped together and welded together to form a welded joint, thereafter the bond number was calculated and recorded.The tungsten non consumable electrode having diameter $3 \mathrm{~mm}$ was used in experiment. The argon gas is used as a shielding gas. The pressure regulator was used to adjust the gas flow rate during operation. The filler metal ER309L having $2 \mathrm{~mm}$ diameter was used for the welding. The direct current Electrode positive (reverse polarity) was used for the welding

\section{Materials used for the experiment}

Low carbon Steel is found in almost every product created from metal. It is easily weldable, very durable and affordable. Tungsten electrode was used as it has a very high melting point making it possible for it to melt other metals easily and its said to be non-consumable.

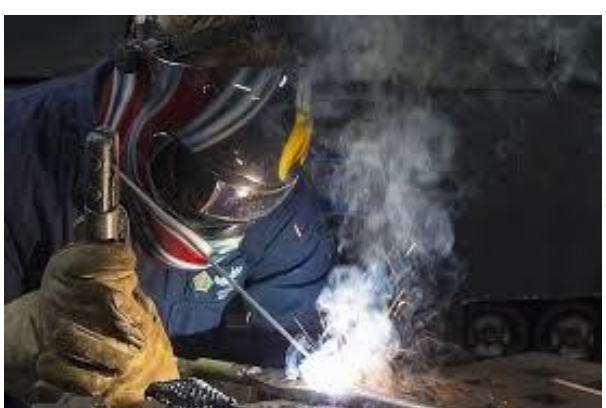

Fig 2:- TIG welding process

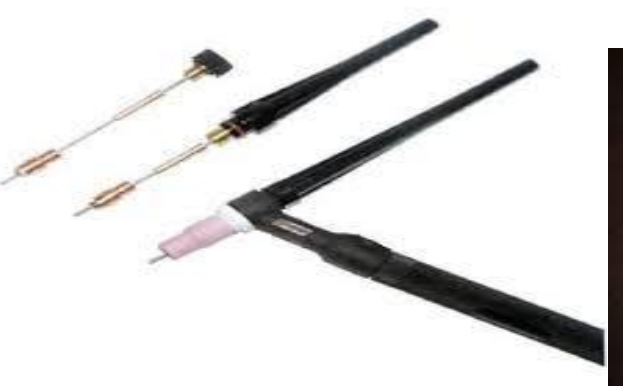

Fig 3:- TIG welding torch

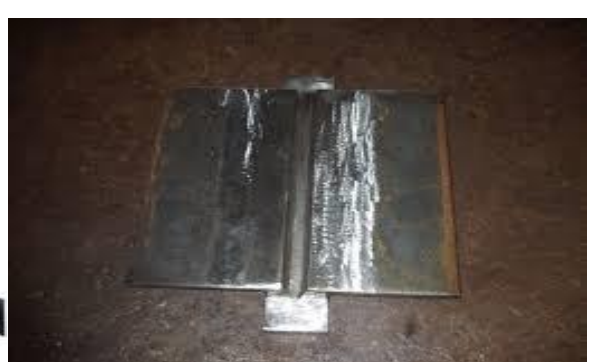

Fig 4:- mild steel weld sample

\section{RESULTS AND DISCUSSION}

In this study, an attempt is made to develop a second order mathematical relationship between selected input variables, namely; current (I), voltage (V) wire diameter (WD) wire feed rate (WFR) to maximize, bond number, using response surface methodology (RSM).

The first step taken in modeling of an RSM model is to validate the suitability of the quadratic model in analyzing the experimental data, and the the sequential model sum of squares was calculated to check for the best model ,the bond number sequential sum of squares is in table 3 .

\begin{tabular}{|c|c|c|c|c|c|c|}
\hline & Sum of & & Mean & $\mathrm{F}$ & p-value & \\
\hline Source & Squares & $\mathrm{df}$ & Square & Value & Prob $>F$ & \\
\hline Mean vs Total & 53.23 & 1 & 53.23 & & & \\
\hline Linear vs Mean & 8.16 & 4 & 2.04 & 2.35 & 0.0822 & \\
\hline 2FI vs Linear & 0.43 & 6 & 0.072 & 0.064 & 0.9987 & \\
\hline $\begin{array}{c}\text { Quadratic vs } \\
\text { 2FI }\end{array}$ & 18.08 & 4 & 4.52 & 20.88 & $<0.0001$ & Suggested \\
\hline $\begin{array}{l}\text { Cubic vs } \\
\text { Quadratic }\end{array}$ & 0.82 & 8 & 0.10 & 0.30 & 0.9449 & Aliased \\
\hline Residual & 2.42 & 7 & 0.35 & & & \\
\hline Total & 83.14 & 30 & 2.77 & & & \\
\hline
\end{tabular}

Table 3:- Sequential model sum of square for bond number 
In table 3 the quadratic model was selected as the most suitable as having the lowest p-value less than 0.05.In assessing the strength of the quadratic model towards minimizing the bond number one way analysis of variance (ANOVA) table was generated which is presented in table 4.

\begin{tabular}{|c|c|c|c|c|c|c|}
\hline & Sum of & & Mean & $\mathrm{F}$ & p-value & \\
\hline Source & Squares & Df & Square & Value & Prob $>F$ & \\
\hline Model & 26.67 & 14 & 1.90 & 8.80 & $<0.0001$ & significant \\
\hline A-current & 7.87 & 1 & 7.87 & 36.34 & $<0.0001$ & \\
\hline B-voltage & $8.167 \mathrm{E}-004$ & 1 & $8.167 \mathrm{E}-004$ & $3.773 \mathrm{E}-003$ & 0.9518 & \\
\hline $\mathrm{C}$-wire diameter & 0.19 & 1 & 0.19 & 0.90 & 0.3583 & \\
\hline D-wire feed rate & 0.10 & 1 & 0.10 & 0.47 & 0.5041 & \\
\hline $\mathrm{AB}$ & 0.046 & 1 & 0.046 & 0.21 & 0.6506 & \\
\hline $\mathrm{AC}$ & 0.084 & 1 & 0.084 & 0.39 & 0.5424 & \\
\hline $\mathrm{AD}$ & 0.044 & 1 & 0.044 & 0.20 & 0.6582 & \\
\hline $\mathrm{BC}$ & 0.058 & 1 & 0.058 & 0.27 & 0.6135 & \\
\hline $\mathrm{BD}$ & 0.19 & 1 & 0.19 & 0.89 & 0.3593 & \\
\hline $\mathrm{CD}$ & $4.225 \mathrm{E}-003$ & 1 & $4.225 \mathrm{E}-003$ & 0.020 & 0.8907 & \\
\hline$A^{\wedge} 2$ & 0.010 & 1 & 0.010 & 0.048 & 0.8303 & \\
\hline $\mathrm{B}^{\wedge} 2$ & 7.36 & 1 & 7.36 & 34.02 & $<0.0001$ & \\
\hline $\mathrm{C}^{\wedge} 2$ & 6.01 & 1 & 6.01 & 27.77 & $<0.0001$ & \\
\hline $\mathrm{D}^{\wedge} 2$ & 8.47 & 1 & 8.47 & 39.12 & $<0.0001$ & \\
\hline Residual & 3.25 & 15 & 0.22 & & & \\
\hline Lack of Fit & 0.93 & 10 & 0.093 & 0.20 & 0.9848 & not significant \\
\hline Pure Error & 2.31 & 5 & 0.46 & & & \\
\hline Cor Total & 29.92 & 29 & & & & \\
\hline
\end{tabular}

Table 4:- ANOVA table for minimizing bond number

The anova table shows us the process parameters having the most significant influence on the minimization of the bond number response and the current is observed to have a very significant effect on the response with a p-value of $<0.0001$.To obtain the optimal solution, we first consider the coefficient statistics and the corresponding standard errors. The computed standard error measures the difference between the experimental terms and the corresponding predicted terms. Coefficient statistics for bond number response variable is presented in table 5.

\begin{tabular}{|c|c|c|c|c|c|c|}
\hline & Coefficient & & Standard & $95 \% \mathrm{CI}$ & $95 \% \mathrm{CI}$ & \\
\hline Factor & Estimate & Df & Error & Low & High & VIF \\
\hline Intercept & 2.55 & 1 & 0.19 & 2.15 & 2.95 & \\
\hline A-current & -0.57 & 1 & 0.095 & -0.77 & -0.37 & 1.00 \\
\hline B-voltage & $-5.833 \mathrm{E}-003$ & 1 & 0.095 & -0.21 & 0.20 & 1.00 \\
\hline C-wire diameter & -0.090 & 1 & 0.095 & -0.29 & 0.11 & 1.00 \\
\hline D-wire feed rate & 0.065 & 1 & 0.095 & -0.14 & 0.27 & 1.00 \\
\hline $\mathrm{AB}$ & 0.054 & 1 & 0.12 & -0.19 & 0.30 & 1.00 \\
\hline $\mathrm{AC}$ & -0.072 & 1 & 0.12 & -0.32 & 0.18 & 1.00 \\
\hline $\mathrm{AD}$ & -0.052 & 1 & 0.12 & -0.30 & 0.20 & 1.00 \\
\hline $\mathrm{BC}$ & -0.060 & 1 & 0.12 & -0.31 & 0.19 & 1.00 \\
\hline $\mathrm{BD}$ & 0.11 & 1 & 0.12 & -0.14 & 0.36 & 1.00 \\
\hline $\mathrm{CD}$ & -0.016 & 1 & 0.12 & -0.26 & 0.23 & 1.00 \\
\hline $\mathrm{A}^{\wedge} 2$ & 0.019 & 1 & 0.089 & -0.17 & 0.21 & 1.05 \\
\hline $\mathrm{B}^{\wedge} 2$ & -0.52 & 1 & 0.089 & -0.71 & -0.33 & 1.05 \\
\hline $\mathrm{C}^{\wedge} 2$ & -0.47 & 1 & 0.089 & -0.66 & -0.28 & 1.05 \\
\hline $\mathrm{D}^{\wedge} 2$ & -0.56 & 1 & 0.089 & -0.74 & -0.37 & 1.05 \\
\hline
\end{tabular}

Table 5:- Coefficient estimates statistics generated for minimizing bond number 
To validate the adequacy of the quadratic model based on its ability to maximize the bond number the goodness of fit statistics presented in table 6 .

\begin{tabular}{|c|c|c|c|}
\hline Std. Dev. & 0.47 & R-Squared & 0.8915 \\
\hline Mean & 1.33 & Adj R-Squared & 0.7902 \\
\hline C.V. \% & 34.93 & Pred R-Squared & 0.7092 \\
\hline PRESS & 8.70 & Adeq Precision & 10.938 \\
\hline
\end{tabular}

Table 6:- Goodness of fit statistics for bond number

The goodness of fit measures the strength and adequacy of the quadratic model. The results obtained shows that the model has $89 \%$ capacity to predict the bond number when any change occurs in any of the input parameters.

To check for errors in the data collected for analysis a statistical computation is done to check for outliers

The generated cook's distance for the bond number is presented in Figures 5
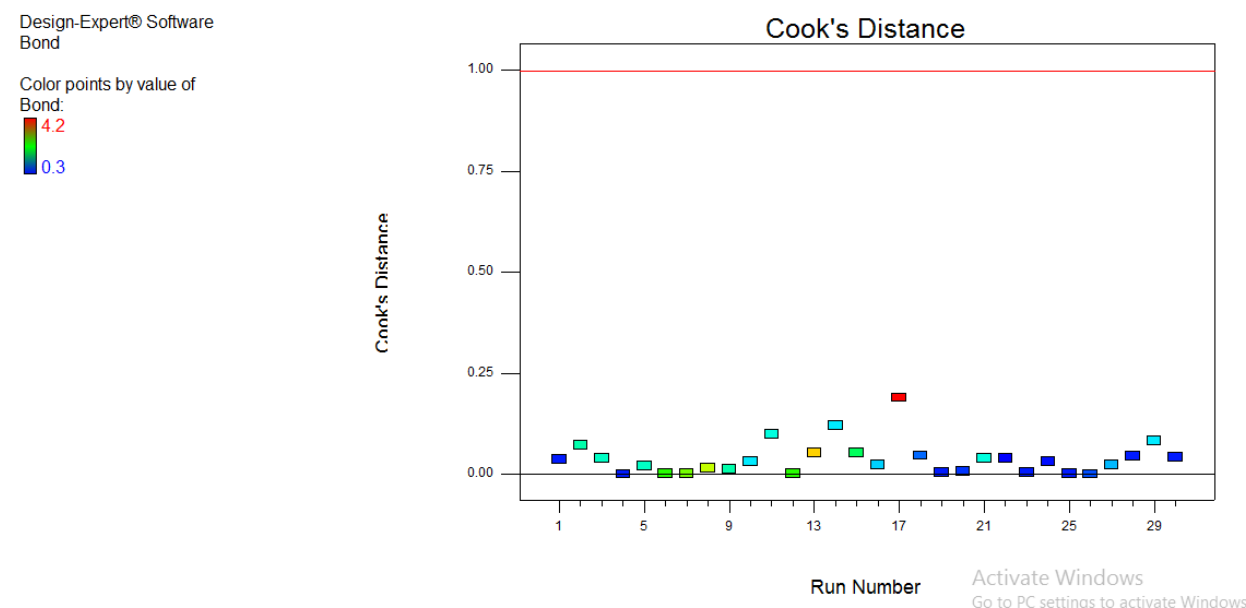

Fig 5:- Generated cook's distance for bond number

The cook's distance observed in figure 5 shows that all the data are statistically significant as they all fall within the range 0 and 1.The design expert software is given a task to minimize the bond number In addition, the optimum current, voltage, wire diameter and wire feed rate was determined simultaneously as shown if figure 6 .

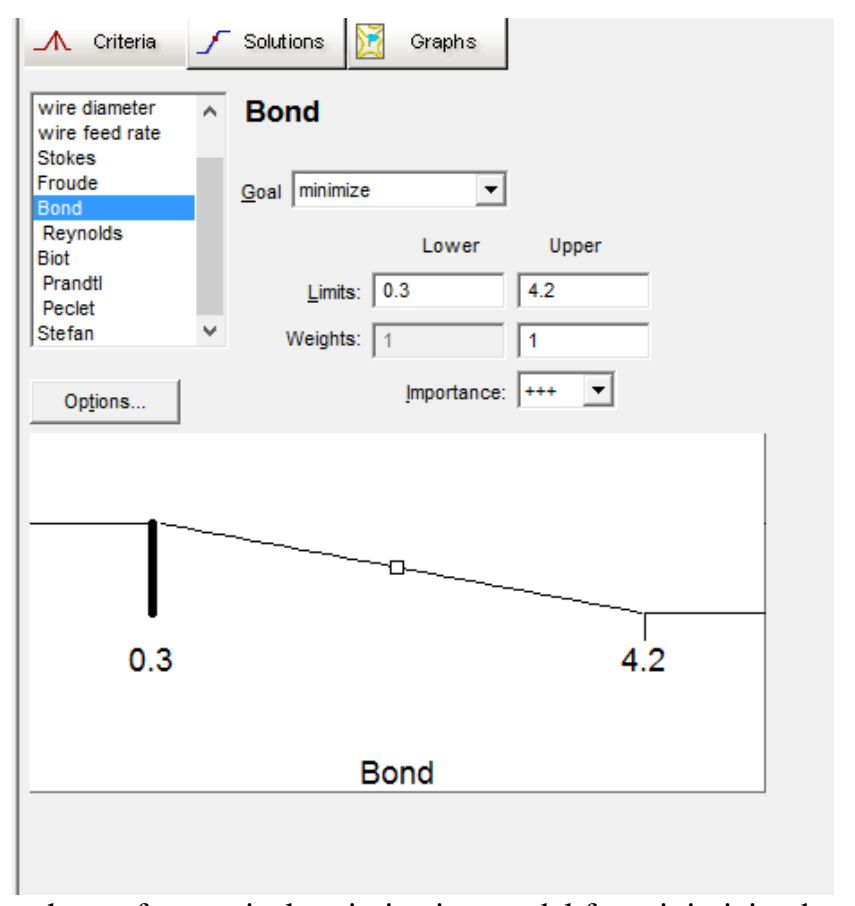

Fig 6:- Interphase of numerical optimization model for minimizing bond number 
The final optimal solution was obtained showing optimal results for current, voltage, wire feed rate and wire diameter that will produce the minimum bond number as shown in table 7.

\begin{tabular}{|c|c|c|c|c|c|c|}
\hline Current & voltage & wire diameter & $\begin{array}{c}\text { wire feed } \\
\text { rate }\end{array}$ & Bond & Desirability & \\
\hline 189.85 & 18.00 & 1.61 & 25.00 & 0.598207 & 0.718 & Selected \\
\hline 189.36 & 18.00 & 1.60 & 25.09 & 0.607241 & 0.718 & \\
\hline 190.00 & 18.07 & 1.60 & 25.00 & 0.624875 & 0.716 & \\
\hline 189.83 & 18.00 & 1.61 & 25.20 & 0.622599 & 0.716 & \\
\hline 187.01 & 18.00 & 1.60 & 25.00 & 0.627228 & 0.715 & \\
\hline 189.99 & 18.00 & 1.65 & 25.00 & 0.623268 & 0.714 & \\
\hline
\end{tabular}

Table 7:- Optimal solutions of numerical optimization model

\section{CONCLUSION}

Molten metal fluidity has been analysed in this study of TIG welding and the bond dimensionless number was maximized. The RSM response surface methodology has been employed to maximize the bond dimensionless numbers. It was observed that the bond number response is strongly influenced by current with a p-value of $<0.0001$. The result obtained shows that the second order quadratic model has adequate strength to predict and minimize the bond number having a coefficient of determination value of $89 \%$ Hence we conclude that minimizing the bond number will help to improve the molten metal fluidity of TIG weld .

\section{REFERENCES}

[1]. Vinith,S., Uthayakumar,A., Senthur, R.S. and Guru Prasadh,G. "Fluidity of ADC12 Alloy Based On Theoretical and Computational Fluid Dynamics "International Journal of Science and Research (IJSR) Volume 4 Issue 5, May 2015

[2]. K. C. Tsao And C. S. Wu" Fluid Flow and Heat Transfer in GMA Weld Pools" Welding Research Supplement March 1988.

[3]. Kamal Touileb ,Rachid Djoudjou and Abousoufiane Ouis "Effect of Viscosity on the GTA Welds Bead Penetration in Relation with Surface Tension Elements" Engineering, Technology and Applied Science Research Vol. 6, No. 2, 2016, 952-955 952

[4]. Won-Kyu Rhim,Kenichi Ohsaka, and Paul-Francois ParadisNoncontact technique for measuring surface tension and viscosity of molten materials using high temperature electrostatic levitation review of scientific instruments volume 70, number 6 june 1999

[5]. Fan (2003)"YAG laser welding with surface activating flux". China Welding (English Edition), 2003. 12(2): p. 83-86.

[6]. McNallan, M.J. and T. Debroy, "Effect of temperature and composition on surface tension in $\mathrm{Fe}-\mathrm{Ni}-\mathrm{Cr}$ alloys containing sulfur". Metallurgical Transactions B, 1991. 22(4): p. 557-560.

[7]. Warinsiriruk E, Poopat B" Investigation of metal transfer of ER705-6 filler metal in MAG-M welding by acoustic signal detection". The Fourth Thailand Material Science and Technology Conference, Bangkok, Thailand, 2006.
[8]. Akhter, R., Steen, W.M., Watkins, K.G., (1991)," Welding zinc-coated steel with a laser and the properties of the weldmen", Journal of Laser Applications, Vol. 3(2), pp 9-20.

[9]. Zhao C, Richardson I M. "Complex Flow Motions during Laser Welding”. 40th AIAA Plasmadynamics and Lasers Conference, San Antonio, Texas, USA, 22 - 25 June, 2009: 250 - 256.

[10]. Jones LA, Eagar T W, and Lang J H.” Metal transfers control in gas metal arc welding". 10th symposium on Energy Engineering Science, Argonne National Lab, Argonne, IL 1992. 